\title{
Pediatric psoriasis: an update
}

This article was published in the following Dove Press journal:

Therapeutics and Clinical Risk Management

20 October 2009

Number of times this article has been viewed

\section{Nanette B Silverberg \\ Pediatric and Adolescent \\ Dermatology, St. Luke's-Roosevelt \\ Hospital Center, New York, NY, USA}

Correspondence: Nanette B Silverberg

Director, Pediatric and Adolescent

Dermatology, St. Luke's-Roosevelt

Hospital Center, 1090 Amsterdam

Avenue, Suite IID, New York,

NY 10025, USA

$\mathrm{Tel}+\mid \mathrm{I} 2125233888$

Fax + I 2125235027

Email nsilverberg@juno.com
Abstract: Pediatric psoriasis consists broadly of 3 age groups of psoriatic patients: infantile psoriasis, a self-limited disease of infancy, psoriasis with early onset, and pediatric psoriasis with psoriatic arthritis. About one-quarter of psoriasis cases begin before the age of 18 years. A variety of clinical psoriasis types are seen in childhood, including plaque-type, guttate, erythrodermic, napkin, and nail-based disease. Like all forms of auto-immunity, susceptibility is likely genetic, but environmental triggers are required to initiate disease activity. The most common trigger of childhood is an upper respiratory tract infection. Once disease has occurred, treatment is determined based on severity and presence of joint involvement. Topical therapies, including corticosteroids and calcipotriene, are the therapies of choice in the initial care of pediatric patients. Ultraviolet light, acitretin and cyclosporine can clear skin symptoms, while methotrexate and etanercept can clear both cutaneous and joint disease. Concern for psychological development is required when choosing psoriatic therapies. This article reviews current concepts in pediatric psoriasis and a rational approach to therapeutics.

Keywords: psoriasis, autoimmunity, Streptococcus, etanercept, calcipotriene, topical corticosteroids

\section{Introduction}

Psoriasis vulgaris is a common dermatologic disorder seen in about $3.5 \%$ of the population. ${ }^{1}$ One-third of psoriasis cases in a dermatology center are pediatric. ${ }^{2}$ Psoriasis is a T-cell mediated chronic inflammatory disorder of the skin characterized by hyper-proliferation of keratinocytes and consequent red scaly skin plaques. Pediatric onset psoriasis is somewhat different than adult disease, as pharyngitis, stress, and trauma are more common triggers of disease activity than in adulthood. ${ }^{3,4}$ Despite the differences in pediatric psoriasis, the therapies used for pediatric psoriasis are essentially the same as those used in adulthood, with dosage and strength reductions calculated based on age, weight, and available formulations. This article looks at a rational approach to the diagnosis and management of pediatric psoriasis, with a careful focus on those aspects of disease unique to the pediatric patient.

\section{Demographics}

About one-third of psoriasis vulgaris cases are seen in the pediatric age group. ${ }^{2}$ Most children manifest with plaque-type psoriasis vulgaris $(68.6 \%)$ in similar patterns to adult patients, with lesions localized to the scalp, post auricular region, elbows, and knees. Guttate disease is more common in pediatric than adult patients, seen in $28.9 \%$ of 277 children in a Chinese survey. Other patterns can be observed in

submit your manuscript $\mid$ www.dovepress.con 
childhood, including erythroderma (1.4\%), pustular disease including palmoplantar pustular psoriasis (1.1\%), and mucosal/glossitis can be observed as pediatric patterns of cutaneous psoriasis. ${ }^{5}$ Diaper involvement is very common in infancy, but involvement of the groin is uncommon in older children. Inverse psoriasis with involvement of the folds of the skin (axillae, inner thighs) represents a small minority of children. Additionally, nail psoriasis can be noted in the setting of plaque-type psoriasis vulgaris, psoriatic arthritis, or with isolated nail disease, the last sometimes being called trachyonychia, although this is controversial. Involvement of joints with psoriatic arthritis is less prevalent in younger patients; however, it does occur in childhood disease and should be considered in the differential of pediatric arthritis. ${ }^{4}$ The annual incidence of psoriasis has been noted to have doubled from 1970 to 2000, but pediatric incidence has not been noted to be increasing. ${ }^{6}$ Psoriasis was not noted in a pediatric population survey of children aged 6 to 11 years in Taiwan, but in China the average age of pediatric psoriasis patients in China was noted to be 11 years, and median age of onset 10 years. ${ }^{5,7}$

Differences of onset between females and males have varied from study to study, with a male to female ratio of $1: 1^{8}$ in the largest survey of 1262 children seen from 1981 to 1995 in a children's hospital in Australia. In adulthood, female psoriatic arthritis patients suffer greater disability than males, but gender differences in childhood have not been reported. ${ }^{9}$ The only ethnic variance in psoriasis vulgaris that has been described is a reduction noted among Inuit people, suggesting that diets high in omega three fatty acids appears to have a preventive effect on psoriatic onset. ${ }^{10}$

\section{Pathogenesis}

The exact pathogenesis of psoriasis has not been completely elucidated; however, it is known to have a genetic basis, as $23.4 \%$ to $71 \%$ of children will have a family history of psoriasis $^{3,8}$ and psoriasis is more common in identical than fraternal twins (65\% to $72 \%$ vs $15 \%$ to $30 \%){ }^{11,12}$ HLA-Cw6 has been known to be a susceptibility gene in psoriasis. ${ }^{12}$

It is understood that upper respiratory infections are a common cause of disease onset in childhood, with $14.8 \%$ having upper respiratory infections ${ }^{3,8}$ and $21.3 \%$ being pharyngeal culture positive for group A beta hemolytic streptococcus (Streptococcus pyogenes). The guttate psoriasis subset may have been linked to inflammatory focus in about two-thirds of cases, and is not caused by a specific subtype of group A beta hemolytic streptococcus, but rather by a host-specific response. ${ }^{2,13,14}$ Cross-reactivity of keratinocytes antigens with streptococcal antigens is thought to initiate psoriatic disease in this setting. ${ }^{15}$

Other infections that have been noted in psoriatic disease are presence of staphylococcal superantigens ${ }^{16}$ and HPV DNA. ${ }^{17}$

No single gene has been found to be responsible for psoriasis vulgaris. A series of genes have been isolated in which mutations have been associated with psoriatic disease, including IL12-B9 (1p31.3), IL-13 (5q31.1), IL-23R (1p31.3), HLABW6 PSORS6 STAT2/IL-23A (12q13.2), TNFAIP3 (6q23.3), and TNIP1 (5q33.1). These genes play a role in Th2 cell and Th17 cell activity as well as NF- $\kappa B$ signaling, demonstrating both a role for Th2 and Th17 lymphocytes in the pathogenesis of psoriatic disease. Th17 cells have been noted in psoriatic lesions, as have collections of Th2 and Th1 cells. ${ }^{12,18,19}$ Susceptibility loci for psoriasis may be shared with Crohn's disease (IL-12B and IL-23R) and ulcerative colitis (IL-23R). As a result, patients with Crohn's disease are 5 times more likely to develop psoriasis than other members of the population. ${ }^{12}$

\section{Relationship to autoimmunity}

Psoriasis is one of more than 80 autoimmune conditions that have been described. Autoimmunity encompasses a broad spectrum of medical diseases in which the body forms an immune reaction against a normal organ, the most common being thyroid disease. Physicians with an interest in learning about the broad spectrum of autoimmunity can access some information on the topic from the National Institutes of Health. ${ }^{20}$

Many patients with psoriasis will have other autoimmune conditions, often of the skin, including morphea ${ }^{21}$ and vitiligo vulgaris (sometimes this association is familial). ${ }^{22}$ Family history of psoriasis and other forms of autoimmunity can be noted in patients with psoriasis and in patients with a personal history of other autoimmune diseases such as multiple sclerosis. ${ }^{23}$ The concurrent incidence of autoimmune thyroiditis in adults has been reported in the literature to be variable, but there is no literature on co-morbid thyroid disease in pediatric psoriasis patients. One Italian study looking at adult patients with psoriatic arthritis $(n=80)$ and age-matched controls, demonstrating a greater incidence of thyroid disease in psoriatic arthritis patients, especially when the psoriatic arthritis patients had concomitant rheumatoid arthritis and in males with psoriatic arthritis. ${ }^{24}$ Other studies have not demonstrated significant increases of thyroiditis markers in adult patients with psoriasis vulgaris compared to age-matched controls. ${ }^{25}$ 
Based on the conflicting data, annual thyroid screening has not been shown to be warranted in children; thyroid screening and screening for autoimmune thyroid disease should be performed in the setting of psoriatic arthritis, as there are some data to support an association of thyroiditis and psoriatic arthritis, and when psoriasis occurs in the presence of other autoimmune diseases such as vitiligo which have been associated which have a stronger association with thyroid disease. ${ }^{26}$

\section{Clinical characteristics and diagnosis (Table I)}

Psoriasis vulgaris occurs in a variety of clinical types, each of which is listed in Table 1. A few clinical features of psoriasis that are pertinent during physical examination include 1) the isomorphic response or Koebner phenomenon, which is occurrence of lesions in areas of trauma, 2) altered pigmentation with lesional clearance, 3) the Auspitz sign - pinpoint bleeding at the base of scale that has been removed, and 4) presence of nail pitting, which can aid in diagnosis of the disease. ${ }^{27}$

Severity grading for psoriasis is usually based on surface area and presence and co-morbid psoriatic arthritis. The Psoriasis Area and Severity Index (PASI) can be used to assess severity (Table 2). Others will divide disease into mild if less than $3 \%$ body surface area, moderate $3 \%$ to $10 \%$ body surface area, and severe $>10 \%$ body surface area. ${ }^{28}$

\section{Differential diagnosis}

The differential diagnosis of psoriasis includes other papulosquamous disorders of childhood including lichen planopilaris, psoriasiform ID reactions, nummular dermatitis, pityriasis rosea, and pityriasis rubra pilaris. Biopsy can be helpful in differentiating psoriasis from these other illnesses.

\section{Treatments}

The treatments of psoriasis have expanded over the past decade; however the use of topical therapy in childhood is the first line of treatment for skin-limited disease, in combination with a trial of oral antibiotics where indicated. With chronicity of illness and in more severe cases, systemic therapy and phototherapy are added to help induce remission. Significant psychological disturbances are seen in children with psoriasis, no matter what the surface area. ${ }^{29}$ Disease, although cutaneous, should be treated more aggressively when it is causing psychological disturbance, to improve quality of life.

\section{Topical therapy}

Topical therapies for pediatric psoriasis include over-the-counter agents such as tar and salicylic acid, the latter of which aids in removal of hyperkeratosis. Tar has been a controversial medication in pediatric psoriasis, especially when combined with ultraviolet light in the Goeckermann regimen, because of demonstrable genotoxic risk, including chromosomal aberrations in peripheral lymphocytes and release of heat shock protein. ${ }^{30}$ Prescription agents for psoriasis vulgaris in childhood include anthralin, ${ }^{31}$ topical corticosteroids, topical calcipotriene with or without topical corticosteroids, and topical calcineurin inhibitors. Below the age of 12 years there have been no topical agents approved specifically by the FDA for treatment of psoriasis vulgaris in childhood. Off-label usage has been well described in the literature for childhood psoriatic disease, and all of the topical agents mentioned appear effective at times for pediatric psoriasis. Formulations chosen and strengths should be determined based on patient age, PASI score, quality of life, and patient age.

Anthralin 1\% or dithranol are rarely used for localized areas and can cause localized irritation. ${ }^{31}$ Topical clobetasol has been approved for use in children ages 12 and over in some formulations and can be quite effective for use in psoriatic lesions in adolescents, but runs a risk of atrophy because of class I status. ${ }^{32}$ In pediatric psoriasis topical corticosteroids are usually prescribed similarly to prescriptions in atopic dermatitis of childhood. Low- to mid-potency corticosteroids, class 5-7, are chosen for facial and intertriginous lesions, while mid-potency class $2-4$, are chosen for extremities and the scalp. ${ }^{33}$ Topical corticosteroids run a risk of local atrophy and systemic absorption, the latter becoming more likely if used for larger surface areas. Topical calcipotriene $^{34}$ or calcitriol can be used for pediatric psoriasis, the latter being well tolerated for sensitive skin. ${ }^{35}$ Side effects are generally limited to local intolerance or irritation. Systemic absorption and alteration of calcium levels are a theoretical risk; however, they are unlikely if used on limited body surface area. Topical calcineurin inhibitors, tacrolimus $0.3 \%$ ointment, ${ }^{36}$ and pimecrolimus $1 \%$ can be beneficial for pediatric psoriasis, particularly in sites where atrophy is of risk, such as the face, intertriginous areas, and groin. Use in children under the age of 2 years is not recommended by the FDA.

\section{Phototherapy}

Phototherapy is a safe and effective treatment for children old enough to stand still in a phototherapy booth, particularly 


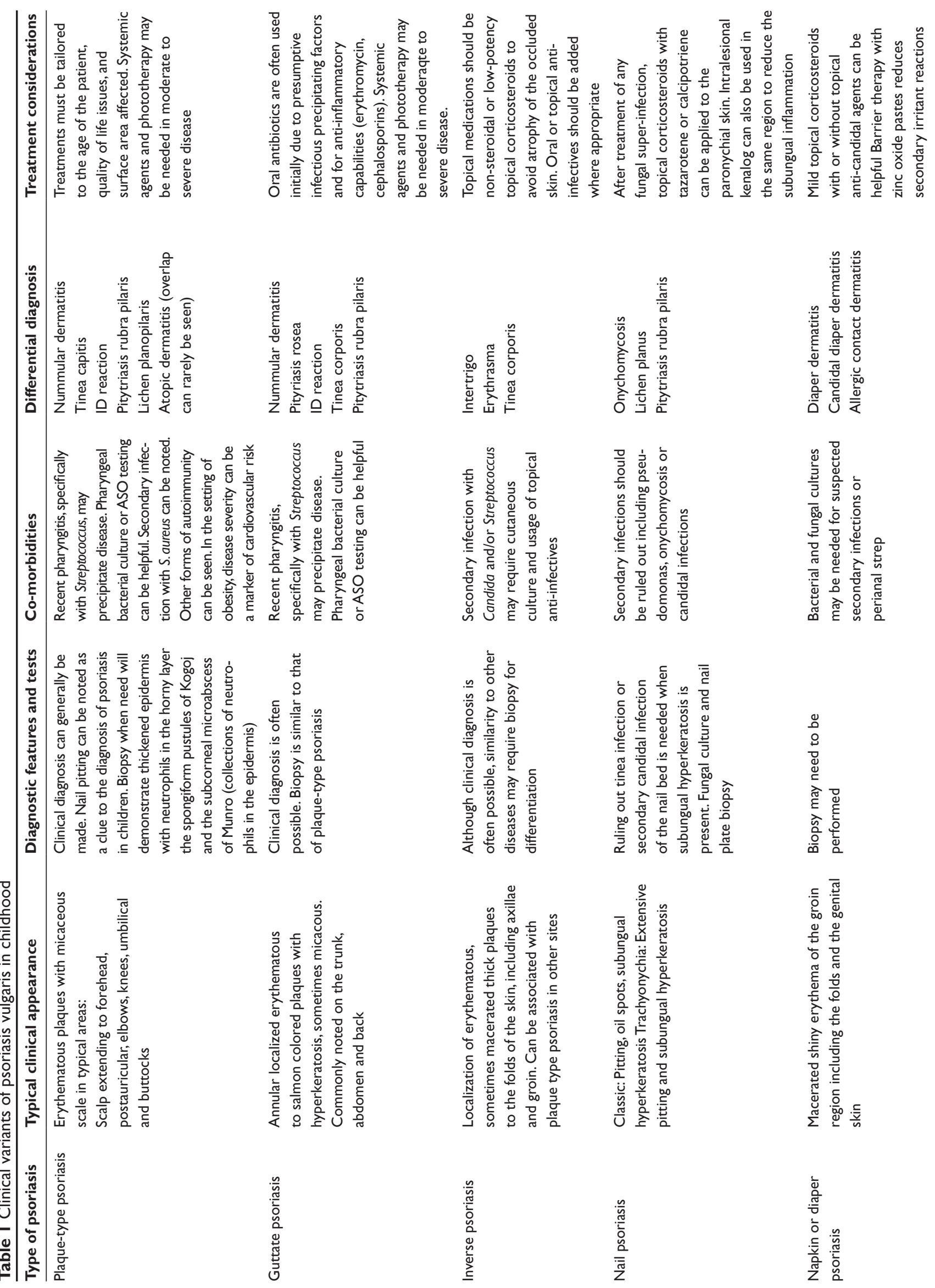



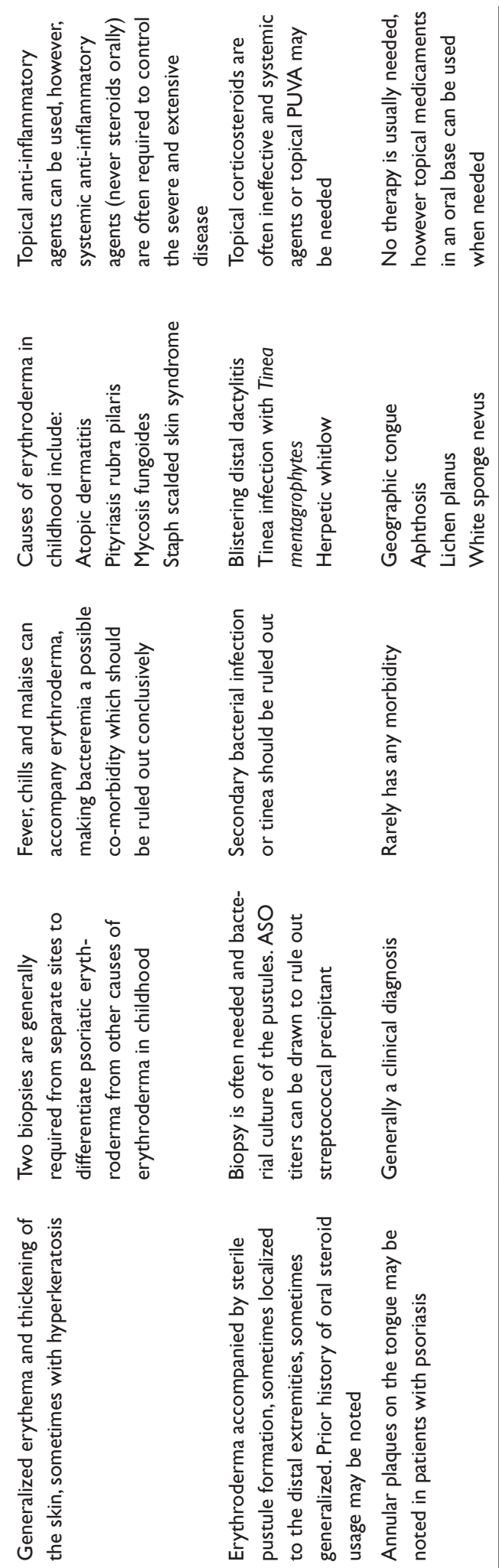

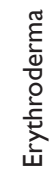

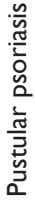

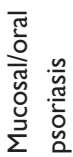

teenagers with extensive disease. Generalized or hand foot therapy, either narrowband UVB (NBUVB) or psoralens and UVA (PUVA), can be used. Topical psoralens are preferable to oral psoralens because of the difficulty of wearing protective eyewear for a 24-hour time period after oral psoralens. As PUVA has been associated with long-term carcinogenicity in psoriatics, NBUVB is likely safer in childhood cases. ${ }^{36-38}$

\section{Systemic agents}

Systemic agents should be saved for severe psoriasis, disabling psychological ramifications, and psoriatic arthritis. Usage of systemic agents is generally limited to a 6-month time period for immunosuppressants such as cyclosporine, acitretin or methotrexate. Longer usage periods have been observed to be safe in rheumatoid arthritis patients on etanercept, however usage beyond a one year time period has not been well assessed in pediatric psoriatics. Methotrexate has been used for pediatric patients for decades longer than etanercept. Oral antibiotics are the systemic therapy of choice in early disease, due to their superior side effect profile.

\section{Oral antibiotics}

Oral antibiotics can be useful in treating psoriasis vulgaris, particularly in the setting of positive oral pharyngeal cultures, presence of perianal bacterial dermatitis, pustular psoriasis, ${ }^{39}$ or in guttate psoriasis of childhood (but not adult guttate disease), as these settings are linked to a bacterial precipitant of psoriasis. ${ }^{40}$ Use of oral antibiotics has demonstrated mixed results, many authors finding mixed results with use. ${ }^{41}$ Oral antibiotics are often used at first sign of psoriasis in children, but no placebo-controlled trials have compared antibiotics with placebo. Furthermore, the ideal regimen of antibiotic use is unknown.

\section{Methotrexate}

When pediatric psoriasis becomes chronic and severe (PASI $>10$ ), systemic therapy provides the major source of improvements in pediatric quality of life. The original psoriatic systemic therapy used for extensive psoriasis is methotrexate, which has been used for over 3 decades for pediatric psoriasis and pediatric psoriatic arthritis. Two recent publications have evaluated cohorts of pediatric psoriatic patients treated with methotrexate. Methotrexate (dosed at 0.2 to $0.7 \mathrm{mg} / \mathrm{kg} /$ week) provides excellent clearance or PASI 75 ( $>75 \%$ PASI reduction) in most children. ${ }^{42}$ While monitoring blood counts and liver function tests are required, liver function alteration is rarely observed and 
Table 2 Psoriasis Area and Severity Index (PASI) score

To determine PASI score, establish grade and severity and then use site-based weighting

Grade: surface area as below (0-6)

$0 \%$ of involved area, grade: 0

- $<10 \%$ of involved area, grade: I

- $10 \%-29 \%$ of involved area, grade: 2

- $30 \%-49 \%$ of involved area, grade: 3

- $50 \%-69 \%$ of involved area, grade: 4

- $70 \%-89 \%$ of involved area, grade: 5

- $90 \%-100 \%$ of involved area, grade: 6

Severity: $0-4$ none to severe

Erythema (redness)

Induration (thickness)

Desquamation (scaling)

Notes: The sum of all three severity parameters is than calculated for each section of skin, multiplied by the area score for that area and multiplied by weight of respective section ( 0.1 for head, 0.2 for arms, 0.3 for body and 0.4 for legs).

seems to be most associated with obesity and consequent fatty liver changes. ${ }^{43,44}$ Methotrexate also has the advantage over cyclosporine in clearing or improving psoriatic arthritis. Therapy is started with a small dosage $(7.5 \mathrm{mg})$ followed by escalating dosages while sequentially monitoring labs. ${ }^{42}$ Addition of folic acid supplementation helps protect against pancytopenia and macrocytic anemia. ${ }^{45}$

\section{Cyclosporine A}

Cyclosporine A, a systemic immunosuppressant used originally for prevention of transplant rejection, can be dosed for oral use at 3 to $5 \mathrm{mg} / \mathrm{kg}$ can improve cutaneous symptomatology in pediatric psoriatic patients. Alterations in renal function with altered serum urea nitrogen and creatinine and high blood pressure can be observed. Therefore, close monitoring is warranted. Risks of malignancy and lymphoproliferative disorders seem to be minimal in children treated for skin diseases due to limited courses of therapy and dosages that are below $5 \mathrm{mg} / \mathrm{kg} /$ day. ${ }^{42,46}$

\section{Retinoids}

Acitretin orally 0.5 to $1 \mathrm{mg} / \mathrm{kg}$ per day has been used for disorders of cornification and psoriasis with good results. Because of teratogenicity, oral contraceptives in girls of childbearing age should be used concurrently, and for 3 years after drug disocontinuation. Short-term side effects, such as elevations in lipids or alterations in blood counts, require monitoring. Long-term changes such as bony abnormalities can occur and treatment periods should be limited, using a cyclic approach. Bony evaluation may be required. ${ }^{42}$

\section{Biologics}

Etanercept and infliximab, injectable and intravenous, respectively, tumor necrosis factor alpha (TNF- $\alpha$ ) inhibitor therapies have been used for a decade in pediatric autoimmune diseases including rheumatoid arthritis, ${ }^{47} \mathrm{TNF}-\alpha$ receptor 1-associated periodic syndrome without fever (TRAPS) ${ }^{48}$ juvenile idiopathic arthritis, ${ }^{49}$ and Crohn's disease. Safety and efficacy data are available for up to 8 years' use in juvenile rheumatoid arthritis. Long-term use did not increase serious side effects. An ACR 70 was achieved by most children treated, with no cases of tuberculosis, opportunistic infections, malignancies, lymphomas, lupus, demyelinating disorders, or death. Long-term improvements on bony disease in arthritis of childhood have been demonstrated with etanercept. ${ }^{50}$

A recent clinical trial described the results of a phase II clinical trial of etanercept in 211 pediatric psoriatics aged 4 to 17 years using a 12 -week, double-blind treatment phase, with a 24 -week open-label phase. At week $12,57 \%$ of patients achieved a PASI 75 compared with $11 \%$ of placebotreated patients $(P<0.001)$ and a PASI 90 was achieved in $27 \%$ of patients compared with $7 \%$ of placebo. Clearance was lost in 29 of 69 patients who withdrew in weeks 36 to 48 weeks. Four serious adverse events including 3 serious infections in children treated with open-label phase, all of which resolved. ${ }^{51}$ These data significantly expand upon prior anecdotal data describing efficacy of etanercept for pediatric psoriasis. ${ }^{52}$ Anecdotal report of a single case that failed etanercept responding to infliximab, suggests this may be an alternative therapy in etanercept-resistant cases. ${ }^{53}$

\section{Natural supplements}

A common question asked by parents of children with psoriasis is "What dietary changes or natural supplements can I give my child to improve their skin disease?" While natural supplements or dietary alterations cannot cure psoriasis, they can improve disease severity. The best-known supplement is fish oil, rich in omega-3 fatty acids. The ingestion of this agent for psoriasis is based upon its preventive effects in the Inuit population. Oral and intravenous supplementation of omega-3 and, less effectively, omega- 6 fatty acids ${ }^{54}$ have been found effective in psoriatic adults, possibly through alterations in production and alterations in arachidonic acid (20:4 omega 6) and docosapentaenoic acid. ${ }^{55}$ Fish meals 4 to 6 times per week can mimic the effects of omega-3 supplementation. ${ }^{56}$

Indigo naturalis, a traditional Chinese medicine, can be formulated into topical ointment with anecdotal reports of good results in childhood psoriasis when used for 8 weeks. ${ }^{57}$ 


\section{Conclusions}

Recent advances in genetics and the unraveling of the processes responsible for psoriatic disease are making possible considerable advancements in the treatment of pediatric psoriasis.

\section{Disclosures}

The author reports no conflicts of interest in the development of this work.

\section{References}

1. Kurd SK, Gelfand JM. The prevalence of previously diagnosed and undiagnosed psoriasis in US adults: results from NHANES 2003-2004. J Am Acad Dermatol. 2009;60:218-224.

2. Raychaudhuri SP, Gross J. A comparative study of pediatric onset psoriasis with adult onset psoriasis. Pediatr Dermatol. 2000;17:174-178.

3. Seyhan M, Coskun BK, Sağlam H, Ozcan H, Karincaoğlu Y. Psoriasis in childhood and adolescence: evaluation of demographic and clinical features. Pediatr Int. 2006;48:525-530.

4. Kumar B, Jain R, Sandhu K, Kaur I, Handa S. Epidemiology of childhood psoriasis: a study of 419 patients from northern India. Int $J$ Dermatol. 2004;43:654-658.

5. Fan X, Xiao FL, Yang S, et al. Childhood psoriasis: a study of 277 patients from China. J Eur Acad Dermatol Venereol. 2007;21:762-765.

6. Icen M. Trends in incidence of adult-onset psoriasis over three decades: a population-based study. J Am Acad Dermatol. 2009;60:394-401.

7. Chen GY, Cheng YW, Wang CY, et al. Prevalence of skin diseases among schoolchildren in Magong, Penghu, Taiwan: a community-based clinical survey. J Formos Med Assoc. 2008;107:21-29.

8. Morris A, Rogers M, Fischer G, Williams K. Childhood psoriasis: a clinical review of 1262 cases. Pediatr Dermatol. 2001;18:188-198.

9. Wallenius M, Skomsvoll JF, Koldingsnes W, et al. Work disability and health-related quality of life in males and females with psoriatic arthritis. Ann Rheum Dis. 2009;68:685-689.

10. Mueller BA, Talbert RL. Biological mechanisms and cardiovascular effects of omega-3 fatty acids. Clin Pharm. 1988;7:795-807.

11. Grjibovski AM, Olsen AO, Magnus P, Harris JR. Psoriasis in Norwegian twins: contribution of genetic and environmental effects. $J$ Eur Acad Dermatol Venereol. 2007;21:1337-1343.

12. Li Y, Begovich AB. Unraveling the genetics of complex diseases: Susceptibility genes for rheumatoid arthritis and psoriasis. Semin Immunol. 2009 May 13. [Epub ahead of print].

13. Nahary L, Tamarkin A, Kayam N, et al. An investigation of ant streptococcal antibody responses in guttate psoriasis. Arch Dermatol Res. 2008;300:441-449.

14. Telfer NR, Chalmers RJ, Whale K, Colman G. The role of streptococcal infection in the initiation of guttate psoriasis. Arch Dermatol. 1992;128:39-42.

15. Pérez-Lorenzo R, Zambrano-Zaragoza JF, Saul A, Jiménez-Zamudio L, Reyes-Maldonado E, García-Latorre E. Auto antibodies to autologous skin in guttate and plaque forms of psoriasis and cross-reaction of skin antigens with streptococcal antigens. Int J Dermatol. 1998;37: 524-531.

16. Balci DD, Duran N, Ozer B, Gunesacar R, Onlen Y, Yenin JZ. High prevalence of Staphylococcus aureus cultivation and superantigen production in patients with psoriasis. Eur J Dermatol. 2009;19: $238-242$

17. Simeone P, Teson M, Latini A, Carducci M, Venuti A. Human papillomavirus type 5 in primary keratinocytes from psoriatic skin. Exp Dermatol. 2005;14:824-829.

18. Lowes MA, Kikuchi T, Fuentes-Duculan J, et al. Psoriasis vulgaris lesions contain discrete populations of Th1 and Th17 T cells. J Invest Dermatol. 2008;128:1207-1211.
19. Hüffmeier U, Lascorz J, Becker T, et al. Characterization of psoriasis susceptibility locus 6 (PSORS6) in patients with early onset psoriasis and evidence for interaction with PSORI. J Med Genet. 2009. June. [Epub ahead of print].

20. http://www3.niaid.nih.gov/topics/autoimmune. Accessed June 16, 2009.

21. Leitenberger JJ, Cayce RL, Haley RW, Adams-Huet B, Bergstresser PR, Jacobe HT. Distinct autoimmune syndromes in morphea: a review of 245 adult and pediatric cases. Arch Dermatol. 2009;145:545-550.

22. Al-Mutairi N, Al-Doukhi A. Familial coexisting and colocalized psoriasis and vitiligo responding to alefacept. J Cutan Med Surg. 2009; 13:172-175.

23. Barcellos LF, Kamdar BB, Ramsay PP, et al. Clustering of autoimmune diseases in families with a high-risk for multiple sclerosis: a descriptive study. Lancet Neurol. 2006;5:924-931.

24. Antonelli A, Delle Sedie A, Fallahi P, et al. High prevalence of thyroid autoimmunity and hypothyroidism in patients with psoriatic arthritis. J Rheumatol. 2006;33:2026-2028.

25. Gul U, Gonul M, Kaya I, Aslan E. Autoimmune thyroid disorders in patients with psoriasis. Eur J Dermatol. 2009;19:221-223.

26. Pagovich OE, Silverberg JI, Freilich E, Silverberg NB. Thyroid abnormalities in pediatric patients with vitiligo in New York City. Cutis. 2008; $81: 463-466$

27. Stern RS, Wu J. Psoriasis. In: Arndt KA, LeBoit PE, Robinson JK, Wintroub BU, eds. Cutaneous Medicine and Surgery. Philadelphia: WB Saunders; 1996.

28. Gottlieb AB, Chaudhari U, Baker DG, Perate M, Dooley LT. The natural psoriasis foundation score (NPF-PS) system versus the Psoriasis Area Severity Index (PASI) and Physicians Global Assessment (PGA): a comparison. J Drugs Dermatol. 2003;2:260-266.

29. Beattie PE, Lewis-Jones MS. A comparative study of impairment of quality of life in children with skin disease and children with other chronic childhood diseases. Br J Dermatol. 2006;155:145-151.

30. Borska L, Andrys C, Krejsek J, et al. Genotoxic hazard and cellular stress in pediatric patients treated for psoriasis with the Goeckerman regimen. Pediatr Dermatol. 2009;26:23-27.

31. Farber EM, Nall L. Childhood psoriasis. Cutis. 1999;64:309-314.

32. Kimball AB, Gold MH, Zib B, Davis MW; Clobetasol Propionate Emulsion Formulation Foam Phase III Clinical Study Group. Clobetasol propionate emulsion formulation foam $0.05 \%$ : review of phase II open-label and phase III randomized controlled trials in steroid-responsive dermatoses in adults and adolescents. $J$ Am Acad Dermatol. 2008;59:448-454.

33. Kiken DA, Silverberg NB. Atopic dermatitis in children, part 2: treatment options. Cutis. 2006;78:401-406.

34. Oranje AP, Marcoux D, Svensson A, et al. Topical calcipotriol in childhood psoriasis. J Am Acad Dermatol. 1997;36:203-208.

35. Liao YH, Chiu HC, Tseng YS, Tsai TF. Comparison of cutaneous tolerance and efficacy of calcitriol 3 microg g $(-1)$ ointment and tacrolimus $0.3 \mathrm{mg} \mathrm{g}(-1)$ ointment in chronic plaque psoriasis involving facial or genitofemoral areas: a double-blind, randomized controlled trial. $\mathrm{Br} \mathrm{J}$ Dermatol. 2007;157:1005-1012.

36. Jain VK, Aggarwal K, Jain K, et al. Narrow-band UV-B phototherapy in childhood psoriasis. Int J Dermatol. 2007;46:320-322.

37. Tay YK, Morelli JG, Weston WL. Experience with UVB phototherapy in children. Pediatr Dermatol. 1996;13:406-409.

38. Pasic A, Ceovic R, Lipozencic J, et al. Phototherapy in pediatric patients. Pediatr Dermatol. 2003;20:71-77.

39. Cassandra M, Conte E, Cortez B. Childhood pustular psoriasis elicited by the streptococcal antigen: a case report and review of the literature. Pediatr Dermatol. 2003;20:506-510.

40. Wilson JK, Al-Suwaidan SN, Krowchuk D, et al. Treatment of psoriasis in children: is there a role for antibiotic therapy and tonsillectomy? Pediatr Dermatol. 2003;20:11-15.

41. Dogan B, Karabudak O, Harmanyeri Y. Antistreptococcal treatment of guttate psoriasis: a controlled study. Int J Dermatol. 2008;47:950-952.

42. Cordoro KM. Systemic and light therapies for the management of childhood psoriasis: part II. Skin Therapy Lett. 2008;13:1-3. 
43. Collin B, Vani A, Ogboli M, Moss C. Methotrexate treatment in 13 children with severe plaque psoriasis. Clin Exp Dermatol. 2009;34: 295-298.

44. Kaur I, Dogra S, De D, Kanwar AJ. Systemic methotrexate treatment in childhood psoriasis: further experience in 24 children from India. Pediatr Dermatol. 2008;25:184-188.

45. Gisondi P, Fantuzzi F, Malerba M, et al. Folic acid in general medicine and dermatology. J Dermatolog Treat. 2007;18:138-146.

46. Davis A, Krafchik BR. New drugs in pediatric dermatology. Curr Opin Pediatr. 1993;5:212-215.

47. Lovell DJ, Reiff A, Ilowite NT, et al; Pediatric Rheumatology Collaborative Study Group. Safety and efficacy of up to eight years of continuous etanercept therapy in patients with juvenile rheumatoid arthritis. Arthritis Rheum. 2008;58:1496-1504.

48. Morbach H, Richl P, Stojanov S, Lohse P, Girschick HJ. Tumor necrosis factor receptor 1-associated periodic syndrome without fever: cytokine profile before and during etanercept treatment. Rheumatol Int. 2009 Apr 19. [Epub ahead of print].

49. Nielsen S, Ruperto N, Gerloni V, et al; Italian Pediatric Rheumatology Study Group. Preliminary evidence that etanercept may reduce radiographic progression in juvenile idiopathic arthritis. Clin Exp Rheumatol. 2008;26:688-692.

50. Lovell DJ, Giannini EH, Reiff A, et al; Pediatric Rheumatology Collaborative Study Group. Long-term efficacy and safety of etanercept in children with polyarticular-course juvenile rheumatoid arthritis: interim results from an ongoing multicenter, open-label, extendedtreatment trial. Arthritis Rheum. 2003;48:218-226.
51. Paller AS, Siegfried EC, Langley RG, et al; Etanercept Pediatric Psoriasis Study Group. Etanercept treatment for children and adolescents with plaque psoriasis. $N$ Engl J Med. 2008;358:241-251.

52. Hawrot AC, Metry DW, Theos AJ, Levy ML. Etanercept for psoriasis in the pediatric population: experience in nine patients. Pediatr Dermatol. 2006;23:67-71.

53. Farnsworth NN, George SJ, Hsu S. Successful use of infliximab following a failed course of etanercept in a pediatric patient. Dermatol Online J. 2005;11:11.

54. Mayser P, Mrowietz U, Arenberger P, et al. Omega-3 fatty acid-based lipid infusion in patients with chronic plaque psoriasis: results of a double-blind, randomized, placebo-controlled, multicenter trial. J Am Acad Dermatol. 1998;38:539-547.

55. Grattan C, Burton JL, Manku M, Stewart C, Horrobin DF. Essentialfatty-acid metabolites in plasma phospholipids in patients with ichthyosis vulgaris, acne vulgaris and psoriasis. Clin Exp Dermatol. 1990;15:174-176.

56. Fahrer H, Hoeflin F, Lauterburg BH, Peheim E, Levy A, Vischer TL. Diet and fatty acids: can fish substitute for fish oil? Clin Exp Rheumatol. 1991;9:403-406.

57. Lin YK, Yen HR, Wong WR, Yang SH, Pang JH. Successful treatment of pediatric psoriasis with Indigo naturalis composite ointment. Pediatr Dermatol. 2006;23:507-510.
Therapeutics and Clinical Risk Management

\section{Publish your work in this journal}

Therapeutics and Clinical Risk Management is an international, peerreviewed journal of clinical therapeutics and risk management, focusing on concise rapid reporting of clinical studies in all therapeutic areas outcomes, safety, and programs for the effective, safe, and sustained use of medicines. This journal is indexed on PubMed Central, CAS,

\section{Dovepress}

EMBase, Scopus and the Elsevier Bibliographic databases. The manuscript management system is completely online and includes a very quick and fair peer-review system, which is all easy to use. Visit $\mathrm{http} / / / \mathrm{www}$.dovepress.com/testimonials.php to read real quotes from published authors. 